\title{
La democracia indígena en América Latina. Experiencias de los procesos electorales de 2021
}

\author{
Manuel Gustavo Ocampo Muñoa*
}

https://doi.org/10.35242/RDE $2022 \quad 22 \quad 33 \quad 11$

Nota del Consejo Editorial

Recepción: 13 de noviembre de 2021

Revisión, corrección y aprobación: 14 de enero de 2022.

Resumen: El presente documento pretende coadyuvar en la promoción y difusión de la cultura democrática y generar reflexión sobre la realidad política y social en los países del continente americano mediante el análisis de la representación política de los pueblos originarios, derivada de los procesos electorales de 2021, tomando como referencia los celebrados en Ecuador, Bolivia, Chile, Perú y México. Lo anterior mediante la identificación de las buenas y malas prácticas en los comicios en relación con los derechos políticos reconocidos a los mencionados pueblos, con la intención de demostrar la urgencia de un principio electoral que promueva el fair play desde el pluralismo jurídico.

Palabras clave: Indígenas / Grupos étnicos / Población indígena / Derechos políticos / Derecho electoral / Derecho constitucional / Igualdad de oportunidades / Representación política.

Abstract: This document aims at contributing to the promotion and dissemination of democratic culture as well as generating reflection on the political and social reality in the countries of the American continent though the analysis of political representation of native peoples derived from the 2021 electoral processes. The study refers to the processes that took place in Ecuador, Bolivia, Chile, Peru, and Mexico. The document presents to best practices as well as the poor practices in terms of acknowledgement of political rights for the peoples. The aim is to demonstrate the urgency of an electoral principle that can foster fair play from the perspective of judiciary pluralism.

Key Words: Indigenous people / Ethnic groups / Indigenous population / Political rights / Electoral law / Constitutional law / Equality of opportunities / Political representation.

\footnotetext{
* Mexicano, abogado, correo manuel.ocampo@iij-unach.mx. Maestro y doctor en Derecho por el Instituto de Investigaciones Jurídicas de la Universidad Autónoma de Chiapas. Profesor investigador de ese mismo Instituto y actualmente, coordinador de Investigación y Posgrado. Ganador en dos ocasiones (2017 y 2019 ) del Concurso Nacional de Ensayo en Materia de Justicia Abierta, Transparencia, Acceso a la Información, Protección de Datos Personales y Archivos organizado por el Tribunal Electoral del Poder Judicial de la Federación. Investigador nacional nivel I del Sistema Nacional de Investigadores del Consejo Nacional de Ciencia y Tecnología CONACyT de México. Investigador científico honorífico del Instituto de Ciencia, Tecnología e Innovación del Estado de Chiapas, México. Miembro de la Sociedad Mexicana de Estudios Electorales, A.C. y del Grupo de Investigación Derecho, Diversidad y Gobernanza del IIJ-UNACH.
} 


\section{DERECHO ELECTORAL}

\section{INTRODUCCIÓN}

El presente documento aborda la democracia indígena en América Latina mediante el análisis de la representación política de los pueblos originarios, derivada de los procesos electorales de 2021, tomando como referencia los comicios celebrados en Ecuador, Bolivia, Chile, Perú y México. En el estudio se identifican las buenas y las malas prácticas de los participantes en relación con los derechos políticos reconocidos a los mencionados pueblos, con el objetivo de demostrar la urgencia de promover, desde el pluralismo jurídico, el juego limpio o fair play en materia electoral. Con fines didácticos, se divide en cinco apartados, el primero corresponde a esta introducción, los restantes a la metodología utilizada, el marco teórico y jurídico de la democracia indígena en América Latina, conclusiones y referencias.

En el apartado destinado al marco teórico y jurídico de la democracia indígena en América Latina, se explica el concepto y su relación con la materia electoral; se describen, además, las prerrogativas que, en materia política, los ordenamientos fundamentales de Ecuador, Bolivia, Perú, Chile y México reconocen a los pueblos originarios.

Con el tópico de buenas y malas prácticas en los procesos electorales de 2021 en los mencionados países, se reflexiona acerca de algunas situaciones que impactaron en la democracia indígena en su orden interno y la necesidad de promover el juego limpio para consolidar la representación política de los pueblos originarios en América Latina.

\section{Metodología}

Para alcanzar el objetivo planteado se toma como referente teórico el enfoque intercultural del derecho y se recurre al pluralismo jurídico para contextualizar el estado que guardan los derechos políticos de las personas indígenas y los reconocidos a los pueblos originarios en América Latina. Se eligen como muestra los procesos electorales de 2021 llevados acabo en Ecuador, Bolivia, Perú, Chile y México, debido a que estos países cuentan con diferentes niveles de aceptación del pluralismo jurídico y ello puede impactar en las buenas o malas prácticas electorales en relación con el ejercicio de los derechos políticos en comento. Con el auxilio de la metodología del derecho comparado se analiza el marco constitucional de los citados Estados y algunos eventos relacionados con las elecciones, que involucran a pueblos originarios o a personas pertenecientes a estos para 


\section{DERECHO ELECTORAL}

identificar si se respetan las reglas que promueven acciones afirmativas de participación política indígena.

\section{MaRCo teórico y JURÍdico de la democracia indígena en AmÉriCa LATINA}

Para los efectos de este trabajo, por democracia indígena se entiende la práctica tradicional colectiva y convenida, cuyo espacio político central es la asamblea comunitaria que, a su vez, es considerada la autoridad máxima dentro del sistema normativo de los pueblos originarios. Por lo anterior, el enfoque intercultural del derecho es pertinente para el análisis de los avances o retrocesos de la democracia indígena en los procesos electorales de 2021 en América Latina, pues se caracteriza por la promoción del diálogo y el respeto a las diferencias culturales.

Una herramienta de la interculturalidad es el pluralismo jurídico, este se manifiesta como un fenómeno de coexistencia de normas que reclaman obediencia en un mismo territorio y que pertenecen a sistemas normativos distintos, cuya característica más importante es el hecho de estar organizados en torno a una norma de reconocimiento (Correas, 1994, pp. 613-624). Por tal motivo, se sostiene que en aquellos Estados en los que aún reconociéndose el derecho indígena, no se permite a los pueblos originarios el ejercicio de funciones jurisdiccionales, siendo atribución exclusiva, en todo caso, de los órganos judiciales estatales, no se puede hablar de la existencia de un auténtico pluralismo jurídico.

El pluralismo jurídico admite, en consecuencia, la diversidad de seres en el mundo, realidades dispares, elementos o fenómenos desiguales y cuerpos sociales semiautónomos irreductibles entre sí, pero que pueden funcionar de manera coordinada (Ansart, 1978, pp. 173-176). El pluralismo jurídico asume diferentes modalidades en el contexto de las sociedades contemporáneas; sin embargo, se distinguen dos tipos básicos: el que niega la posibilidad de un pluralismo jurídico intrasistémico y aquel que afirma su existencia.

La primera visión considera que los campos sociales semiautónomos son los lugares donde se verifica la producción jurídica y que, por lo tanto, un mismo sistema jurídico no puede ser plural. El auténtico pluralismo jurídico es el denominado pluralismo jurídico en sentido fuerte, que se genera cuando se puede verificar la presencia dentro de un grupo social de múltiples órdenes legales, en donde la existencia de un orden legal 


\section{DERECHO ELECTORAL}

separado conlleva la presencia de una regla de reconocimiento distinta: esto es, los órdenes legales separados no son reducibles uno al otro (Griffiths, 1995, pp. 217-227).

Tal pluralismo se caracteriza por ser destructivo, pues pretende romper el dominio absoluto de un orden normativo jerárquico único, unificado y exclusivo que depende del poder del Estado. Argumenta que cuando se incluyen dentro de un mismo sistema normas pertenecientes a otro, se está en presencia de un pluralismo jurídico en sentido débil, el cual no es otra cosa que un ajuste de un sistema cuya ideología básica es el monismo jurídico. En sentido débil, un sistema jurídico es pluralista cuando el soberano establece regímenes jurídicos diferentes para grupos diferentes de la población, es decir, es un subtipo particular de fenómenos jurídicos dentro de la ideología centralista (Griffiths, 1986, pp. 152-153).

A partir del año 1994, la teoría del derecho y la teoría sociológica del derecho reaccionan en América Latina, en particular en México, para hacer frente y responder a las preguntas que surgen de la irrupción del mundo indígena en la política cotidiana. Este pluralismo promueve que los pueblos indígenas ocupen un espacio cada vez mayor en la vida política (Correas, 2010, pp. 71-82).

En Latinoamérica, el pluralismo jurídico propone un proyecto de nuevo derecho al servicio de la justicia, la emancipación y la dignificación de los seres humanos; desde una perspectiva jurídica, pluralista, democrática y antidogmática que realmente atienda el contexto en el que se encuentran los países latinoamericanos (Wolkmer, 2006, p. 26). También se visibiliza en esta parte del mundo una constante intersección de diferentes órdenes legales como consecuencia de que vivimos en un momento de legalidad porosa o de porosidad legal, de múltiples redes de órdenes legales que nos obligan a constantes transiciones e intrusiones; fenómeno que se identifica como interlegalidad (Santos, 2010, p. 15).

Con apoyo en el pluralismo jurídico es posible verificar si en los procesos electorales celebrados en 2021 en Latinoamérica se respetaron los derechos políticos de los pueblos originarios, pues permite identificar las buenas y malas prácticas de los diferentes actores políticos en lo relativo a la coexistencia de dos o más sistemas normativos. Por lo que resulta factible en este trabajo, en relación con los pueblos y comunidades originarias de Latinoamérica, establecer los siguientes cuestionamientos en torno al proceso electoral de 2021: ¿Qué posibilidad jurídica tuvieron 


\section{DERECHO ELECTORAL}

las personas que pertenecen a un pueblo o comunidad originaria de participar como candidatas o candidatos?; ¿existieron mecanismos para garantizar niveles mínimos de representación política de las poblaciones originarias?; ¿cuántas personas pertenecientes a pueblos o comunidades originarios accedieron a un cargo público? Por otro lado, para identificar la relación que se establece entre el desarrollo constitucional del pluralismo jurídico y la democracia indígena en América Latina, se analizan, además, los ordenamientos fundamentales de Ecuador, Bolivia, Perú, Chile y México, a manera de descripción del escenario electoral 2021 en la región.

En el Ecuador coexisten 14 nacionalidades y 18 pueblos indígenas descendientes de los grupos originarios que lo poblaron desde hace miles de años, y su presencia histórica determina el carácter pluricultural y multiétnico del país. De acuerdo al preámbulo, inciso tercero de la Constitución de la República, el derecho a la diversidad étnico-cultural representa un valor sobre el que se fundamenta la Constitución al proclamar que es voluntad del pueblo ecuatoriano consolidar la unidad de la nación ecuatoriana en el reconocimiento de la diversidad de sus regiones, pueblos, etnias y culturas (Congreso Nacional de la República del Ecuador, 2020).

Es así que se establece de manera precisa el carácter plurinacional e intercultural del Estado. Estas características deben entenderse como la base del reconocimiento y funcionamiento del pluralismo jurídico; que se expresa de forma clara al describir el derecho a conservar y desarrollar sus propias formas de convivencia y organización social, y ejercicio de la autoridad, en sus territorios legalmente reconocidos y tierras comunitarias de posesión ancestral; así como a construir y mantener organizaciones que los representen (Congreso Nacional de la República del Ecuador, 2020, artículo 57).

Cuando la Constitución asume como principio la multietnicidad y pluriculturalidad, está ordenando al Estado ecuatoriano actuar de una manera especial y particular con los ciudadanos que ostentan una condición étnica y cultural determinada, esto significa que en una situación específica, si para la población en general algo es válido y aplicable, para la población indígena o afroecuatoriana puede que no lo sea por su condición cultural y étnica. La Constitución asume también la igualdad proporcional al establecer principios y normas que sustentan tratos diferentes para los pueblos indígenas. La diferenciación tiene que 


\section{DERECHO ELECTORAL}

ver con el otorgamiento de facultades autonómicas como medio para garantizar la diferencia cultural y étnica.

La especificación de los pueblos indígenas y afroecuatorianos como grupos que se han mantenido en una situación histórica de desigualdad y exclusión social permite a la Constitución reconocerles unos derechos especiales y específicos, mediante los cuales sea posible eliminar un foco de discriminación. Las reivindicaciones de los pueblos indígenas han ganado un espacio en la esfera jurídica y en la vida de los ciudadanos, en especial para los indígenas y los afroecuatorianos. Se considera que quedan por resolver paradigmas desde la ciencia del derecho, ante la perspectiva iuspluralista (Díaz y Antúnez, 2017, pp. 15-44).

En el caso de Bolivia, para entender el pluralismo existente a nivel constitucional se debe tomar en cuenta que se arrastra desde la época colonial un sistema de exclusión que ha persistido en toda la historia del país, y que propició la subordinación de los indígenas, negros y campesinos (Garcés, 2013, p. 45). Fue hasta 1994 cuando se realiza una movilización denominada "Marcha por la vida, la coca y la soberanía" que a la par de consolidar las alianzas de los pueblos indígenas trae la exigencia de la convocatoria a una asamblea constituyente, por lo que se comienza a buscar cada vez un mayor apoyo y representación política (Do Alto, 2007, p. 36).

En ese contexto, los indígenas en el año 2000, cansados de la implementación de políticas públicas que solo generaban un agravamiento de la pobreza, exclusión, racismo y violencia, exigieron la reconstrucción del Estado boliviano, desconociendo la lógica de la construcción histórica del Estado-nación que no hacía más que legitimar su situación de inferioridad (Soruco, 2011, p. 78).

A partir de la Constitución Política del Estado Plurinacional de Bolivia promulgada en febrero de 2009, se observa un reconocimiento más detallado de los grupos indígenas, acompañado de diferentes preceptos, cuyo objetivo principal es la reivindicación de los sectores indígenas. En ella se define claramente su modelo de Estado como plurinacional comunitario, intercultural, con autonomías, que se funda en el pluralismo jurídico dentro de un proceso integrador del país ${ }^{1}$. Reconoce, además, que

\footnotetext{
1 Preámbulo de la Constitución Política del Estado Plurinacional de Bolivia, se observa el mismo sentido, aunque menos incisivo, en el Preámbulo de la Constitución de la República del Ecuador.
} 


\section{DERECHO ELECTORAL}

son diversas naciones las que constituyen el Estado plurinacional, asume el respeto a sus distintas cosmovisiones, y establece que son idiomas oficiales el castellano y todos los idiomas de las naciones y pueblos indígenas (Constitución Política del Estado de Bolivia, artículo 1). El modelo de Estado Plurinacional implica que los pueblos y naciones indígena originario campesinos estén representados en los poderes públicos, y que deba reconocerse la existencia y ejercicio de sus sistemas políticos propios con pleno respeto a sus usos y costumbres, a través del voto universal.

En las elecciones subnacionales del 7 de marzo de 2021 se eligieron 25 escaños especiales de asambleístas reservados para la representación de los pueblos indígena originario campesinos (PIOC) minoritarios asentados en ocho de los nueve departamentos, cuya elección se basa en procedimientos propios y supeditados a los principios de equivalencia de género (CAOESTE, 2021, párrs. 4-6). En la actualidad, de 272 asambleístas, 25 son escaños especiales reservados para la representación de los PIOC asentados en ocho de los nueve departamentos, cuya elección se basa en procedimientos propios y supeditados a los principios de equivalencia de género.

En lo que respecta al Estado peruano, desde 1995 es parte del Convenio 169 de la Organización Internacional del Trabajo (OIT), que tiene rango constitucional y, por tanto, es de obligatorio cumplimiento en ese Estado; sin embargo, al parecer, el avance normativo para el reconocimiento de los pueblos indígenas es limitado, disperso y contradictorio (Palacín, 2011, pp. 26-43). Es un país pluriétnico y pluricultural en el que se hablan 47 idiomas distintos y se reúnen alrededor de 55 pueblos indígenas, esto es aproximadamente el $14 \%$ de la población.

Los pueblos indígenas no son reconocidos como tales por la Constitución, solo han sido identificados como comunidades campesinas en la costa y los Andes, y como comunidades nativas en la Amazonía, a las que se reconoce personalidad y son consideradas autónomas en su organización, en el trabajo comunal y en el uso y la libre disposición de sus tierras, así como en lo económico y administrativo, dentro del marco legal. Se reconoce, además, el derecho a la participación política de las comunidades campesinas y nativas, y pueblos originarios en los consejos regionales al menos en los porcentajes mínimos que establece la ley de la materia. 


\section{DERECHO ELECTORAL}

Por su parte, en Chile el marco normativo de los pueblos originarios se integra por la Constitución Política de la República; los instrumentos internacionales ratificados por Chile y referidos a la temática, el Convenio 169 de la OIT sobre Pueblos Indígenas y Tribales en Países Independientes y la Declaración de Derechos de los Pueblos Indígenas (DDPI); su legislación secundaria que establece normas sobre protección, fomento y desarrollo de los indígenas y que crea la Corporación Nacional de Desarrollo Indígena (CONADI) en la denominada ley indígena.

La Constitución Política de la República no contiene un artículo que se refiera a los derechos de los pueblos originarios ni tampoco al carácter multicultural de la población chilena. La vía que han adoptado los pueblos indígenas para hacer exigibles judicialmente sus derechos ha sido la utilización de los tratados internacionales sobre derechos y la invocación de derechos constitucionales, tales como la igualdad ante la ley, libertad de culto, el derecho de propiedad y el derecho a vivir en un medio ambiente libre de contaminación.

En Chile, se ha destacado la creciente aplicación por parte de los tribunales nacionales del Convenio 169 de la OIT y de la Declaración de Naciones Unidas sobre Derechos de Pueblos Indígenas para interpretar y reforzar su contenido en la jurisprudencia nacional. La Ley Indígena reconoce a los indígenas, a sus principales etnias y comunidades, y establece el deber del Estado de respetar, proteger y promover el desarrollo de los indígenas y sus culturas y proteger sus tierras, por medio de la adopción de medidas para tal efecto. Esta ley establece derechos políticos y de participación, identifica las tierras indígenas y les otorga protección y reconoce el derecho de los indígenas a mantener y desarrollar sus propias manifestaciones culturales.

El Congreso chileno despachó una ley que asegura 17 escaños reservados para representantes de los pueblos originarios en la Convención Constitucional que redactará la nueva Constitución en 2021. El cambio fue decidido por una amplia mayoría del $79 \%$ en el plebiscito que tuvo lugar el 25 de octubre de 2020. Los 17 cupos serán determinados por el Servicio Electoral (SERVEL) dentro de los 155 escaños por elegir en los distritos electorales ya establecidos, los mismos en los que se eligen actualmente los miembros de la Cámara de Diputados. Los mapuches tendrán siete escaños; dos serán para el pueblo Aymara; mientras que los pueblos Atacameños, Colla, Rapa Nui, Yámana, Kawashkar, Diaguita, Quechua y Chango tendrán un representante cada uno (La Jornada, 2020, 


\section{DERECHO ELECTORAL}

párrs. 6 y 7). Los pueblos originarios representan cerca del $12 \%$ de la población total de Chile, de casi 18 millones de habitantes.

En lo que respecta a México, con el levantamiento armado del ejército zapatista en el estado de Chiapas del 1 de enero de 1994 se inicia un movimiento social que deriva hacia la demanda del cumplimiento del Estado mexicano ante los pueblos originarios que habitan el territorio nacional. Después de este movimiento y la firma de los acuerdos de San Andrés Larrainzar sobre derechos y cultura indígena, fue con la reforma constitucional de 2001, fundamentalmente en el artículo segundo, que se definen las reglas explícitas del constitucionalismo mexicano en relación al reconocimiento de derechos colectivos de estos pueblos.

Se fijan, además, las características de las poblaciones para ser consideradas pueblos indígenas y se alude al contenido del Convenio 169 de la OIT, el cual refiere a la conciencia de identidad indígena como criterio fundamental para determinar a quiénes se aplican las disposiciones sobre pueblos indígenas. En ese sentido es pertinente aclarar que, en la actualidad, el criterio aceptado es el cultural, también denominado de la autoadscripción, lo que se traduce en que una persona es indígena si acepta su pertenencia a un pueblo indígena, se identifica con su cultura, actúa conforme a ella y el pueblo indígena al que se adscribe la reconoce como parte de él.

Se establece que tanto el Gobierno federal, como los gobiernos estatales y los municipales deben diseñar instituciones específicas que atiendan la problemática indígena, las cuales deben ser operadas junto con representantes de los pueblos y comunidades indígenas. Se reconoce, además, el derecho de pueblos y comunidades indígenas para decidir libremente la forma en que organizarán su vida interna política, económica y cultural. En lo político existen las condiciones para que puedan elegir su representación bajo los sistemas de cargos, reconocimiento de principales y Consejo de Ancianos. Aunado a lo anterior, se reconoce el derecho a los pueblos y comunidades indígenas para elegir, de acuerdo con sus normas, procedimientos y prácticas tradicionales, a las autoridades o representantes para el ejercicio de sus formas propias de gobierno interno, garantizando la participación de las mujeres en condiciones de equidad frente a los varones, en un marco que respete el pacto federal, la soberanía de los Estados y los derechos humanos. 


\section{DERECHO ELECTORAL}

En noviembre del 2020, el Consejo General del Instituto Nacional Electoral, mediante Acuerdo INE/CG572/2020, aprobó los criterios para el registro de candidaturas a diputaciones federales para el proceso electoral federal 2020-2021, en cuyo punto décimo séptimo, se estableció que para el caso de diputaciones por el principio de mayoría relativa, los partidos políticos nacionales o coaliciones deberán postular, como acción afirmativa, fórmulas integradas por personas que se autoadscriban como indígenas en los 21 distritos electorales federales con población indígena distribuidos en las entidades federativas de Chiapas, Guerrero, Hidalgo, Oaxaca, Puebla, San Luis Potosí, Veracruz y Yucatán, de las cuales 11 deberían ser mujeres.

De los derechos políticos descritos se obtiene que las políticas de reconocimiento de derechos a los pueblos originarios establecidas al día de hoy, desde el pluralismo jurídico, se pueden agrupar en tres amplios sectores. El primero lo conforman aquellos países cuyas constituciones niegan la existencia del pluralismo jurídico, es decir, que, aun reconociendo la existencia de los pueblos indígenas, no asumen la existencia de otra legalidad, $y$, por lo tanto, no establecen mecanismos para reconocer el sistema normativo indígena. El segundo grupo lo integran los países con constituciones que lo asumen difusamente, es decir, que, reconociendo la existencia de los pueblos indígenas y sus derechos, asumen que tienen un sistema jurídico y autoridades propias. Si bien han cumplido con elevar a rango constitucional la existencia de una jurisdicción indígena, a esta se le considera como una jurisdicción cuyo ámbito de aplicación es muy restringido, no se establecen reglas constitucionales para su operación y se deja toda la regulación a la ley ordinaria. Por último, el tercer sector es el de las constituciones que lo asumen institucionalmente, es decir, que reconocen la existencia de los pueblos indígenas, de su autogobierno y su propio derecho, la consideran parte de la jurisdicción del Estado e incluso reconocen la existencia de la jurisdicción indígena. Se construyen reglas constitucionales de operación a partir de las cuales se tendrán que desarrollar las leyes ordinarias respectivas que han de incluir la coordinación de los sistemas normativos de los pueblos originarios con el estatal.

A continuación, se describen algunas situaciones que impactaron en la democracia indígena, y que pueden considerarse como acciones contrarias a la letra y al espíritu de las leyes en materia electoral dentro de los procesos celebrados en Ecuador, Bolivia, Chile, Perú y México, durante el año 2021. Tales situaciones consistieron en obstrucción al ejercicio de 


\section{DERECHO ELECTORAL}

derechos políticos reconocidos a los pueblos originarios, prácticas electorales desleales, infracciones reiteradas a las medidas que aseguran el denominado piso parejo en las elecciones y utilización inapropiada de medios de comunicación y redes sociales.

\section{Buenas y malas prácticas en los procesos electorales 2021 en Ecuador, Bolivia, Chile, Perú y México}

En Ecuador se realizaron elecciones presidenciales y legislativas el 7 de febrero de 2021. La participación en conjunto de la Confederación de Nacionalidades Indígenas del Ecuador (CONAIE), organización que aglutina en su seno a las nacionalidades, pueblos, comunidades, centros y asociaciones indígenas del Ecuador y el Movimiento Pachakutik integrado por varios sectores y organizaciones sociales: indígenas, campesinos, afroecuatorianos, trabajadores públicos y privados, mujeres, jóvenes, cristianos de base, ecologistas, intelectuales comprometidos, etc.; generó que el voto indígena estuviera cerca de impulsar a la segunda ronda a su candidato Yaku Pérez, sin embargo esto no ocurrió.

Según la página oficial del Consejo Nacional Electoral de Ecuador (CNE), el ganador de la primera ronda fue Andrés Arauz, de la Unión por la Esperanza (UNES), con 3032906 de votos, un 32,72\% del escrutinio. En segunda posición, el centroderechista Guillermo Lasso, de la alianza (CREO-PSC), con 1829378 votos, lo que representa un 19,74\% del escrutinio. Yaku Pérez, del movimiento indígena Pachklutik, se confirma en la tercera posición con 1796542 votos (19,38\%), y en cuarta el también izquierdista Xavier Hervás con 1453460 votos (15,68\%). La segunda ronda, con esos datos, sería entre Arauz y Lasso; sin embargo, dada la estrecha diferencia de votos con el tercer candidato, Pérez, el CNE se vio en la obligación de calificar las peticiones de recuento entre estos.

El Movimiento Pachakutik externó que fue el Consejo Nacional Electoral (CNE), la máxima autoridad de los comicios, el que puso a los candidatos Arauz y Lasso en la segunda vuelta, y no el resultado de las urnas de votación, y reclamó un recuento de más de 20000 juntas de votación, pero el CNE solo aprobó que se hiciera en 31 de ellas, donde Pérez, que estaba en el tercer lugar con muy poca diferencia de Lasso, sumó una pequeña cantidad de votos respecto del escrutinio preliminar, de ahí lo externado por el Movimiento Pachakutik. En consecuencia, las dos organizaciones indígenas, en principio, coincidieron en no apoyar a ningún 


\section{DERECHO ELECTORAL}

candidato en la segunda ronda; sin embargo, cada una lo planteó de diferente forma; la CONAIE propuso ir por el voto nulo ideológico, mientras que Pachakutik por un voto nulo a secas contra el sistema electoral que, según ese movimiento, avaló un supuesto fraude en el escrutinio de la primera vuelta de las votaciones contra su candidato presidencial.

En Bolivia se llevaron a cabo elecciones subnacionales el 7 de marzo de 2021, las cuales cerraron un ciclo electoral extendido por la pandemia y caracterizado por una severa crisis política postelectoral que siguió a las fallidas elecciones generales presidenciales y legislativas de octubre de 2019, y su posterior anulación. En la recta final del proceso electoral, llamó la atención la inhabilitación del candidato a alcalde de La Llajta, Manfred Reyes Villa, amplio favorito en las encuestas, por parte del Órgano Electoral Plurinacional por su resolución 43 de fecha 21 de febrero de 2021, por corrupción cuando ejercía como gobernador del departamento de Cochabamba entre 2005 y 2008. De lo anterior resulta interesante que el fallo aparece un mes antes de las elecciones, cuando el proceso se inició cuatro años atrás, aproximadamente, lo que hizo pensar que fue manipulado; sorprendió, también, que el expediente fue devuelto a Cochabamba en tiempo récord, pues por lo general ese trámite administrativo demora varias semanas. No obstante, el Tribunal Supremo Electoral (TSE) de Bolivia rehabilita el 3 de marzo al candidato Reyes Villa, con cuatro votos a favor y tres en contra, después de que hiciera efectivos 300000 dólares que adeudaba al Estado por esta condena (Europa press, 2021, párr. 3).

Por otro lado, el indianista radical Santos Quispe, quien ganó la Gobernación de La Paz, llegó a su puesto por herencia, es decir, el candidato original, un legendario líder indianista, era su padre. Este falleció de un infarto en plena campaña, cuando las encuestas lo apuntaban como el favorito. Su agrupación decidió sustituirlo por su descendiente para mantener la influencia de su figura sobre los resultados. Así logró meterse en la segunda vuelta, en la que sumó su propia votación, mayoritariamente indígena, con la de los sectores urbanos anti-MAS ${ }^{2}$. Un aspecto inédito de estas elecciones fue que en La Paz y en Chuquisaca los desempates se produjeron entre dos pares de representantes indígenas (Molina, 2021, párrs. 3-4).

\footnotetext{
2 Movimiento al Socialismo de Bolivia (MAS)
} 


\section{DERECHO ELECTORAL}

Respecto de Chile, hubo elecciones a gobernadores, alcaldes, concejales y constituyentes el 11 de abril; el 9 de mayo la segunda vuelta de gobernaciones y el 4 de julio primarias presidenciales. De acuerdo al Servicio Electoral (SERVEL), solo 282719 personas habilitadas para votar por los escaños reservados para pueblos originarios participaron en las elecciones del 9 de mayo, cifra que representa el 22,81 \% del padrón electoral, compuesto por 1239295 votantes. El pueblo mapuche es el que registró la mayor cantidad de participación, con 217853 votos válidamente emitidos (El mostrador, 2021, párrs. 7-8).

En Perú se hicieron elecciones presidenciales y legislativas el 11 de abril, derivado de estas, un grupo de organizaciones indígenas de la Amazonía y los Andes expresó su rechazo y preocupación ante la ofensiva legal presentada por la candidata a la presidencia, Keiko Fujimori, de Fuerza Popular, que buscaba anular más de 800 actas a nivel nacional -alrededor de 200 mil votos, según los cálculos de dicho partido-, la mayoría de ellas en zonas rurales del país. Para los líderes de estas organizaciones, las acusaciones de fraude son falsas y vulneran el derecho a la participación de las comunidades.

Seis organizaciones de pueblos indígenas respaldadas por la Coordinadora Nacional de Derechos Humanos (CNDDHH) emitieron un pronunciamiento conjunto en el que solicitaron al Jurado Nacional de Elecciones (JNE) resolver con celeridad las solicitudes de nulidad, respetando su derecho al voto. En caso de que estos sean invalidados, anunciaron que presentarán una demanda de amparo e iniciarán movilizaciones masivas.

En regiones como Amazonas, Cusco y Puno, donde el candidato de izquierda Pedro Castillo, de Perú Libre, se impuso con una diferencia de hasta $78,5 \%$, integrantes de comunidades indígenas realizaron manifestaciones en contra de la ofensiva legal de Fuerza Popular.

La Asociación Interétnica de Desarrollo de la Selva Peruana (Aidesep); la Federación Nacional de Mujeres Campesinas, Artesanas, Indígenas, Nativas y Asalariadas del Perú (FENMUCARINAP); la Confederación de Nacionalidades Amazónicas del Perú (CONAP), la Confederación Nacional Agraria (CNA); la Confederación Campesina del Perú (CCP) y la Unión Nacional de Comunidades Aymaras (UNCA); las cuales representan a diferentes comunidades y pueblos indígenas del país, señalaron que detrás del pedido de nulidad de actas de sufragio de Fuerza Popular hay discriminación y racismo (Cabral, 2021, párr. 5). 


\section{DERECHO ELECTORAL}

En México se celebraron elecciones federales y elecciones estatales el 6 de junio. Previo a la contienda electoral, la Red Nacional Indígena (RNI) dirigió un oficio al Instituto Nacional Electoral (INE) y a los representantes de los partidos políticos a fin de exigir el respeto del acuerdo general emitido para garantizar la representación indígena en el proceso electoral del 2021, suscrito en noviembre del 2020 por el Consejo General del INE, mediante Acuerdo INE/CG572/2020. En dicho documento se aprobaron los criterios para el registro de candidaturas a diputaciones federales para el proceso electoral federal 2020-2021, en cuyo punto décimo séptimo, se estableció que para el caso de diputaciones por el principio de mayoría relativa, los partidos políticos nacionales o coaliciones deberán postular, como acción afirmativa, fórmulas integradas por personas que se autoadscriban como indígenas en los 21 distritos electorales federales con población indígena, distribuidos en las entidades federativas de Chiapas, Guerrero, Hidalgo, Oaxaca, Puebla, San Luis Potosí, Veracruz y Yucatán, de las cuales 11 deberían ser mujeres.

El mencionado oficio se debía a que los partidos políticos entregaron sus listas de candidatos y candidatas indígenas plurinominales federales, en las cuales se advirtió que se repiten los agravios cometidos en procesos electorales anteriores, donde se usurpan espacios que corresponderían a auténticos candidatos indígenas; de ahí que la red exigió que se tomaran acciones legales sobre los candidatos y las candidatas que fueron registrados. En lo particular expresaron su preocupación por el distrito I de Palenque, en donde Manuela del Carmen Obrador, según sus oponentes, usurpa una representación que corresponde a los pueblos originarios de esa región. El distrito abarca los municipios de Tila, Sabanilla, Tumbalá, Yajalón, Catazajá, La Libertad y Salto de Agua, y tiene un 74,19 por ciento de población indígena, en especial la población mayense chol y tseltal; sin embargo, la diputada federal palencana pese a no ser indígena pretende reelegirse y continuar usurpando el espacio por el hecho de ser la prima del presidente Andrés Manuel López Obrador (Morales, 2021, párr. 6).

Se señaló, además, el caso del distrito II de Bochil, donde Adela Ramos Juárez desplazó a los candidatos indígenas. Asimismo, en el distrito III Ocosingo, Jesús Oropeza Nájera usurpa el espacio de los candidatos indígenas, y en el distrito $\mathrm{V}$ de San Cristóbal de Las Casas, Martha Decker Gómez usurpa una candidatura indígena en dos periodos electorales. Aunado a que en el distrito XI de Las Margaritas, Roberto Antonio Rubio Montejo, también usurpó la candidatura indígena en dos periodos 


\section{DERECHO ELECTORAL}

consecutivos. De igual manera el Partido Revolucionario Institucional decidió pasar por alto la sentencia del Tribunal y los lineamientos del INE al no incluir a ningún candidato indígena (hombre o mujer) en las cinco circunscripciones federales plurinominales. En ese mismo sentido, en la IV Circunscripción Plurinominal Federal demandaron examinar la acreditación indígena de Esther Araceli Gómez Ramírez, quien fue postulada por el partido Morena como candidata indígena plurinominal (Morales, 2021, párr. 7).

Con todo lo expuesto, se advierte, como una nota distintiva, la existencia en los cuatro países de situaciones que dejan ver una especie de juego sucio de los participantes en los comicios y las autoridades en el ejercicio del poder, así como de los órganos que gestionan y califican las elecciones, por lo que se propone impulsar su contraparte: el denominado juego limpio o fair play. Se trata de un concepto del mundo de los deportes que hace referencia al juego transparente, a la ética deportiva, a la competencia justa, al cumplimiento de las reglas, así como al comportamiento honesto y correcto que deben observar los atletas ante su oponente, el árbitro y los asistentes; se caracteriza por poner en primer lugar el gusto de competir limpiamente y disfrutar el deporte por encima de la ambición de victoria (Carvhalo, 2001, p. 17).

De esta manera, el fair play electoral implica el respeto al contrincante, al árbitro y a las reglas; practicar el juego limpio, sin trampas, trucos o simulaciones para confundir al contrincante o a la autoridad electoral, así como asumir la derrota con dignidad y disfrutar la victoria con sencillez y respeto. Así, gestos como un saludo amistoso al adversario, una disculpa luego de una acción indebida, entre otras formas de proceder, son acciones que manifiestan el espíritu de competir limpiamente en las elecciones.

La intención del fair play electoral es evitar al máximo todo tipo de conductas o comportamientos que afecten los procesos electorales, por ejemplo, irrespeto a las reglas, a las autoridades, a los rivales, a los propios compañeros de partido y a los electores. Ese tipo de comportamientos pueden venir no solo de las candidatas o candidatos, sino también de las dirigencias de partidos políticos, autoridades en ejercicio de sus funciones e, incluso, de familiares. 


\section{DERECHO ELECTORAL}

\section{CONCLUSiones}

Se ha demostrado que en los procesos electorales de 2021 desarrollados en Ecuador, Bolivia, Chile, Perú y México, se advierten situaciones que generan opacidad en los comicios, en las autoridades en el ejercicio del poder y en los órganos que gestionan y califican las elecciones; tales circunstancias son una constante en América Latina.

En el desarrollo de los procesos electorales en los países de referencia se aprecia que, pese a existir acciones afirmativas que promueven la participación política de las personas pertenecientes a pueblos originarios, ya sea como parte de los lineamientos de los institutos electorales u ordenadas por ley, no se garantiza el cumplimiento efectivo. Esto es, por un lado, que las personas que ocupen un escaño designado para un pueblo originario, realmente pertenezcan a este 0 , por otro, que los partidos políticos les impidan alcanzar incluso una candidatura. Además, las mujeres indígenas siguen sin poder participar en condiciones de equidad frente a los varones, pese a formar parte de colectivos que promueven los derechos humanos o de partidos políticos que dicen generarles espacios de participación.

Es pertinente promover el juego limpio o fair play desde el pluralismo jurídico; es decir, generar esta práctica que fortalezca la representación política de los pueblos originarios, mediante reglas que impulsen y replanteen el respeto al contrincante, al árbitro y a la normatividad misma; promover la práctica del juego limpio sin trampas, trucos o simulaciones para confundir al contrincante o a la autoridad electoral; impulsar el diálogo para no ofender, humillar ni maltratar a ningún participante de la contienda, así como asumir la derrota con dignidad y disfrutar la victoria con sencillez y respeto.

\section{Referencias bibliográficas}

Ansart, P. (1978) Ideologias, conflitos e poder. Rio de Janeiro: Zahar.

Asamblea Legislativa Plurinacional de Bolivia. (2020). Constitución Política del Estado de Bolivia.

Cabral, E. (10 de junio 2021). Fujimori presenta ofensiva legal cuando Castillo la supera en votos en actas procesadas. Ojo público. Recuperado de 


\section{DERECHO ELECTORAL}

https://ojo-publico.com/2798/ofensiva-legal-de-fujimori-cuando-castillola-supera-en-conteo-de-onpe

Carvalho, A. (2001). O contributo das organizações nacionais e internacionais na promoção da ética desportiva e do fair play. A importancia da educação para a ética-o olimpismo, en AA. VV., O Desporto e o Direito (prevenir, disciplinar, punir)(pp. 17-26). Lisboa: Livros Horinte.

Conferencia Americana de Organismos Electorales Subnacionales por la Transparencia Electoral (CAOESTE). (2021). Bolivia. Elecciones Subnacionales 2021: el cierre de un ciclo electoral accidentado y maratónico. CAOESTE. Recuperado de https://transparenciaelectoral.org/caoeste/bolivia-elecciones-subnacionales2121-el-cierre-de-un-ciclo-electoral-accidentado-y-maratonico/

Congreso Nacional de la República del Ecuador. (2020). Constitución de la República de Ecuador.

Correas, O. (1994). Ideología jurídica, derecho alternativo y democracia. Boletín mexicano de Derecho Comparado, 27(81), 613-624.

Correas, O. (2010). Cultura jurídica, poder judicial y pluralismo jurídico, En Caballero, J y otros, Sociología del derecho. Culturas y sistemas jurídicos comparados. Regulación, cultura jurídica, multiculturalismo, pluralismo jurídico y derechos humanos (vol. 2) (pp. 71-82). México: UNAM.

Díaz, E. y Antúnez A. (2017). El derecho alternativo en el pluralismo jurídico ecuatoriano. Revista Lex de la Facultad de Derecho y Ciencia Política de la Universidad Alas Peruanas, 15(20), 15-44.

Do Alto, H. (2007). Cuando el nacionalismo se pone el poncho: una mirada retrospectiva a la etnicidad y la clase en el movimiento popular boliviano (1952-2007). En Svampa, M. y Stefanoni, P. (Eds.), Bolivia: memoria, insurgencia y movimientos sociales (pp. 21-54). Buenos Aires: CLACSO.

EI TSE rehabilita al candidato opositor Reyes Villa, favorito para las locales de Bolivia del domingo (3 de marzo 2021). Europa press. Recuperado de https://www.europapress.es/internacional/noticia-tse-rehabilitacandidato-opositor-reyes-villa-favorito-locales-bolivia-domingo20210303225852.html

Garcés F. (2013). Los indígenas y su Estado (pluri)nacional: una mirada al proceso constituyente boliviano. Argentina: CLACSO. 


\section{DERECHO ELECTORAL}

Griffiths, J. (1995). Four Laws of Interaction in circumstances of Legal Pluralism: First steps toward an explanatory theory, en Allot Anthony y Woodman Gordon (Coord.), Peoples' Law and State Law: The Bellangio Papers (pp. 217-227). England: Forist Publications.

Griffiths, J. (1986). What Is Legal Pluralism. Journal of Legal Pluralism, (24), 149-155.

La Jornada. (15 de diciembre 2020). Aprueban 17 escaños indígenas para redactar nueva Constitución chilena. La jornada. Recuperado de https://www.jornada.com.mx/notas/2020/12/15/politica/aprueban-17escanos-indigenas-para-redactar-nueva-constitucion-chilena/

Molina, F. (13 de abril 2021). El partido de Evo Morales sufre un traspié en la segunda vuelta de las elecciones regionales de Bolivia. El País. Recuperado de https://elpais.com/internacional/2021-04-13/el-partidode-evo-morales-sufre-un-traspie-en-la-segunda-vuelta-de-las-eleccionesregionales-de-bolivia.html

Morales, Y. (4 de abril 2021). Exhiben a 5 candidatos y candidatas a diputaciones federales de usurpar puestos indígenas. Chiapas Paralelo. Recuperado de https://www.chiapasparalelo.com/noticias/chiapas/2021/04/exhiben-a-5candidatos-y-candidatas-a-diputaciones-federales-de-usurpar-puestosindigenas/

Palacín Quispe, M. (2011). Los derechos de los pueblos indígenas en la constitución y las leyes, América Latina en movimiento. Jalisco, México: Comisión Estatal del Derechos Humanos.

Participación indígena: $22,81 \%$ del padrón votó escaños reservados para pueblos originarios (17 de mayo 2021). El mostrador. Recuperado de https://www.elmostrador.cl/dia/2021/05/17/participacion-indigena-2281del-padron-voto-escanos-reservados-para-pueblos-originarios/

Soruco, X. (2011). Apuntes para un Estado plurinacional. La Paz, Bolivia: Vicepresidencia del Estado Plurinacional de Bolivia.

Sousa de, B. (2010). Refundación del Estado en América Latina. Perspectiva desde una epistemología del sur. Perú: Instituto Internacional de Derecho Social y Programa Democracia y Transformación Global.

Wolkmer, A. (2006). Pluralismo jurídico. Fundamentos de una nueva cultura del derecho. Madrid: Dykinson. 